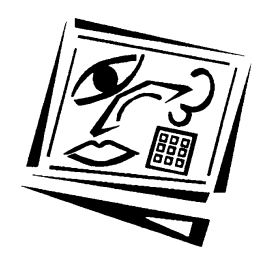

\title{
University students' online information searching strategies in different search contexts
}

\author{
Meng-Jung Tsai, Jyh-Chong Liang, Huei-Tse Hou and Chin-Chung Tsai \\ National Taiwan University of Science and Technology
}

\begin{abstract}
This study investigates the role of search context played in university students' online information searching strategies. A total of 304 university students in Taiwan were surveyed with questionnaires in which two search contexts were defined as searching for learning, and searching for daily life information. Students' online search strategies were evaluated by the "Online Information Searching Strategy Inventory" (Tsai, 2009b). The results of paired t-tests indicated that university students' online search strategies utilised for searching daily life information were significantly better than those utilised for learning activities, especially in behavioural and metacognitive strategies. This study also drew a subsample of 20 students from the participants for in-depth interviews, to explore further the reasons for these findings. We suggest that educators need to pay more attention to helping students develop online search strategies for academic activities. In addition, only female students' metacognitive strategies were significantly different between search contexts. There may be an effect of the interaction between search context and gender on students' online searching strategies. Based on the above, suggestions are provided for future design and implementation of online information searching activities.
\end{abstract}

\section{Introduction}

Integrating information technology into teaching has been promoted in universities for decades. Searching information on the Internet has become a common learning activity in university teaching in all subject domains. Students are often required to search information via the Internet in order to finish and turn in their homework or research projects (Fleiszer \& Posel, 2003; Levine, Bebermeyer, Chen, Davis \& Harty, 2008; McGreevy, Shaw, Burn \& Miller, 2009; Phelps, Fisher \& Ellis, 2006; Tekinarslan, 2008). However, online information searching and processing is a complex cognitive process involving multifaceted cognitive and metacognitive strategies (Hill, 1999; Marchionini, 1995; Tsai \& Tsai, 2003; Tsai, 2009b). Many prior studies (Bos, 2001; Debowski, 2001; Dias, Gomes \& Correia, 1999) reported that students often had disorientation problems and were not be able to evaluate online information critically. Recent research (Bond, Fevyer \& Pitt, 2006; Chu \& Law, 2008; Walraven, Brand-gruwel \& Boshuizen, 2008; Phelps et al., 2006; Tekinarslan, 2008) indicated that even graduate students and adult learners also had troubles with specifying search terms, judging search results, judging source and information as well as regulating the search process.

Tsai and Tsai (2003) proposed a three dimensional framework for analysing searching strategies. Following this study, an instrument was developed by Tsai (2009b) and metacognitive domain strategies were regarded as the most critical strategies to determine search outcomes. Laxman (2009) also conducted a baseline study for 
students' information literacy proficiencies. Tsai, Hsu \& Tsai (2012) further observed searching strategies from a perspective of implicit versus explicit strategies framework. They found reading time and evaluation strategies were important predictors and therefore suggested a further examination on implicit strategies. On the other hand, Laxman (2010) found that training for Internet information searching strategies was required for students' ill-structured problem solving. Topics or contexts of online enquiries could be one of the factors that influence students' use of online information searching strategies. In order to help students utilise effectively and critically online information for learning, educators and information literacy librarians must understand how students search online information, profile students' online information searching strategies and examine the factors influencing their search strategies.

\section{Prior research}

Online information searching strategies have been explored in several prior studies that examining factors influencing search strategies or behaviours. For example, Rieh (2002) found that topic interest affects users' acceptance of a web document. Others indicated that students' cognitive styles (Kim, 2001), Internet self-efficacy (Tsai \& Tsai, 2003), web experience (Thatcher, 2008) and epistemological beliefs (Tu, Shih \& Tsai, 2008) played important roles in students' online searching strategies. Corredor (2006) reported that students' prior domain-specific content knowledge influences goal setting process and general prior knowledge influences content use. However, searching strategies are dependent on the nature of tasks or the contexts (Thatcher, 2008; Tu, Shih \& Tsai, 2008). Recently, Laxman (2010) found that different levels of searching strategies might be required for well and ill-structured problem solving. Not many studies have been conducted to directly examine the role of searching contexts for the students' searching strategies.

Gender is always an important research issue for Internet usage (Chou \& Tsai, 2007; Keasar, Baruch \& Grobgeld-Dahan, 2005; Li, 2005). Regarding gender differences in online search strategies, Large, Beheshti and Rahman (2002) found that boys were more active searchers than girls in formulating more queries, clicking on more hyperlinks per minute, and following up on more hits, spending less time viewing individual pages and jumping pages more frequently. Roy and Chi's (2003) study showed that eighth-grade boys were successful searchers because of their horizontal search move and they tended to filter information at an early stage in the search cycle; whereas vertical search moves were more typical of girls and they were more linear and thorough navigators. Tsai $(2009 \mathrm{~b})$ examined high school students' online search strategies and reported that male students had better behavioural and procedural strategies than females, but no significant difference was found between their metacognitive strategies. However, the interaction between gender and search contexts has not been particularly examined in the prior literature. Therefore, the present study also tried to explore whether male and female students utilise online searching strategies differently in different search contexts.

\section{Theoretical framework}

In order to profile the cognitive and metacognitive strategies used by students while searching information on the web, Tsai and Tsai (2003) proposed a framework for analysing students' online information searching strategies. In this framework, search 
strategies were divided into three domains: behavioural, procedural and metacognitive domains. The behavioural domain described skills required for basic Internet manipulation and navigation. The procedural domain concerned with content-general searching approaches on the Internet. The metacognitive domain indicated skills involved in higher-order and content-related reflective activities on the Internet. In addition, seven aspects of web search strategies were identified under these three domains:

1. Behavioural domain:

i. Control aspect: skills required for manipulating the Internet searching applications.

ii. Disorientation aspect: learners' self-awareness of their searching orientation.

2. Procedural domain:

iii. Trial and error aspect: skills in trying different search approaches.

iv. Problem solving aspect: skills and commitment to overcome problems or frustrations resulting from searching.

3. Metacognitive domain:

v. Purposeful thinking aspect: skills required for search process of self-monitoring.

vi. Select main ideas aspect: skills to identify key concepts of information searched from the Internet.

vii. Evaluation aspect: skills to judge and organise information obtained from the Internet.

According to this framework, Tsai (2009b) further developed an instrument, the Online Information Searching Strategies Inventory (OISSI), in order to evaluate students' online search strategies in a large scale with good validity and reliabilities. The present study, based on this framework and using the OISSI instrument, aimed to explore the role of search context in university students' online information searching strategies and also examine gender differences in university students' online search strategies.

\section{Purpose}

The purpose of this study was to examine the role that online searching context played in university students' online information searching strategies. In particular, this study attempted to compare university students' online information searching strategies utilised in a learning context, with those utilised in a daily life context. Therefore, two search contexts were defined in this study: Context A means to search information on the Internet for learning, for example, doing homework via an online searching task; Context B refers to search information on the Internet for entertainment, for example, searching for news of a famous Taiwanese pop singer via the Internet. The research questions for this study include: Is there any significant difference between university students' online information searching strategies utilised in context A and those utilised in context B? If yes, in which domain or aspect of search strategies do the differences exist? Furthermore, do the differences in search strategies come from both male and female students?

\section{Method}

This study compared university students' online information searching strategies utilised for learning contexts and for daily life contexts. This study applied a two-stage research design. In the first stage, to answer the research questions listed in the above section, this study used a survey including an instrument, Online Information Searching 
Strategies Inventory (OISSI) (Tsai, 2009b), to examine university students' online information strategies in two search contexts. Two search contexts, as aforementioned, were defined and specified in the questionnaire. A total of 304 university students majoring in information management at three technological universities in Taiwan were surveyed. Following the quantitative analysis of the data, this study further conducted the second-stage qualitative analysis of the differences between the two contexts found in the quantitative analysis. In the second stage, an additional sampling of 20 students (10 males and 10 females) was drawn from the initial sample, and indepth interviews were conducted to better understand and further examine the various possible reasons for the first stage findings.

\section{Sample}

The sample of this study was drawn from three technological universities in north Taiwan. A total of eight classes including 304 undergraduates received a questionnaire and served as a pool of follow-up interview subjects for this study. All of the students were majoring in information management and their average age was 21.8 years. They self-reported an average online time of 28 hours/week. Therefore, the samples were Internet experienced users with similar educational backgrounds. Thus, they were suitable for responding to the survey items, including those of assessing their strategies for online information searching. Finally, 296 valid questionnaires were used for data analyses. All activities were conducted in Chinese and translations were made by the authors.

\section{Instrument}

This study used the Online Information Searching Strategies Inventory (OISSI) (Tsai, $2009 b$ ) to evaluate the participating subjects' online search strategies in both search contexts. The OISSI included 25 items to examine the students' online search strategies by the following seven subscales with corresponding sample items. According to Tsai (2009b), the seven subscales are consistent with the seven aspects reviewed above.

- Control (CON): Sample item: "I know how to utilise advanced-search functions provided by search engines."

- Disorientation (DIS): Sample item: "I always feel lost while searching information on the Internet." For this subscale, the students with higher scores mean a lower possibility of disorientation because the item scores had been reversed before summing the total for this subscale.

- Trial and error (TE): Sample item: "I try some other search engines when my search is not successful."

- Problem solving (PS): Sample item: "I do my best to resolve any problem occurring during a search."

- Purposeful thinking (PPT): Sample item: "I keep on reminding myself of the purpose for searching online."

- Select main ideas (SMI): Sample item: "I look through titles or hyperlinks in a web in order to catch major information."

- Evaluation (EVA): Sample item: "I keep on evaluating the relationships among the information searched from the web."

Each item was measured in a 6-point Likert scale ranging from 1 (not like me at all) to 6 (very much like me). Therefore, the total score of the OISSI ranged from 25 to 150 . A higher score on the total or each subscale indicates a better overall strategy or sub- 
strategy. According to Tsai (2009b), the OISSI demonstrated satisfactory validity and reliability for assessing students' online information searching strategies. The reliability alpha value of the OISSI ranged from 0.64 to 0.88 for each subscale and it was 0.91 for the total scale, which were sufficient for examination. The instrument used in this study is attached in the Appendix.

In addition to the seven sub-scores, according to Tsai (2009b) and Tsai and Tsai (2003), three domain scores, that is, behavioural, procedural and metacognitive, can also be obtained by using the instrument for examining search strategies at a macro level. The scores in CON and DIS are related to the students' searching behaviours; therefore the CON and DIS sub-scores are merged to the Behavioural domain score. The scores of TE and PS are merged to the Procedural domain score, since these two subscales concern content-general searching approaches. The Metacognitive domain score is merged from the PPT, SMI and EVA sub-scores because these three subscales involved higher-order and content-related reflective skills. As a result, by using the OISSI instrument, this study yielded a total of 10 sub-scores for representing the students' searching strategies, including seven aspect scores (e.g., CON and EVA) and three domain scores (e.g., Behavioural).

\section{Data collection}

In the first stage, a survey was conducted in October 2010 in order to collect the subjects' online information searching strategies in different search contexts. A questionnaire including the 25 OISSI items and questions about students' background information (e.g. age, gender and web usage experience) was administered to all subjects. In order to collect students' online information searching strategies in both a learning context and in a daily life context, two search contexts were defined and described in the beginning of the questionnaire as the following: Context A indicates to search information on the Internet for learning, for example, doing homework via an online searching task; Context B indicates to search information on the Internet for entertainment, for example, searching for news of a famous Taiwanese pop singer via the Internet. In the questionnaire, each subject was asked to respond to each OISSI item twice in regarding to the both contexts. Therefore, in spite of the students' background information, this study collected 25 OISSI item scores for context A and 25 OISSI item scores for context B for each subject. All of the background information and OISSI item scores were used for data analyses in this study.

In the second stage, a follow-up interview was conducted in which we focused on the strategies with significant differences found in the two contexts measured by the OISSI. A total of 20 subjects with such a characteristic were selected for interviewing. The question items of the interview focused on the aforementioned OISSI questionnaires (see Appendix) and centred on students' experiences regarding each search strategy. The two researchers who underwent the same training in interviewing conducted semi-structured interviews with the sampled students, exploring any possible reasons for these differences through extended and in-depth questioning. All the interviews were in Chinese and the quotes were translated by the authors.

\section{Data analysis}

By calculating from each subject's 25 OISSI item scores for context A (learning context) and context B (daily life context), 10 search strategies sub-scores (seven aspect strategies and three domain strategies) were obtained regarding each context for each 
subject. To assess the research questions, multiple paired t-tests were used to examine the difference between students' 10 sub-scores of context A and those of context B for all students. Similar multiple paired t-tests were further used to examine the differences within male students and within female students. However, according to Glass and Hopkins (1996), conducting multiple t-tests would result in a higher possibility of Type I errors, that is, a higher possibility to reject a null hypothesis when it is true. One way to eliminate this error is to adjust the levels of significances used for examining the multiple t-tests by dividing the significant levels by the number of $\mathrm{t}$ tests (Glass \& Hopkins, 1996). Therefore, the authors adjusted all levels of significances for the explanations of all t-tests by dividing the values of significant levels by 10 because 10 t-tests were conducted together in this study for the search strategy subscores. That is, the $\mathrm{p}$ values for significant levels used in this study would be 0.005 , 0.001 and 0.0001 instead of $0.05,0.01$ and 0.001 .

\section{Results}

This study comprises a two-stage analysis. The first stage presents the results of multiple paired t-tests for examining whether there is any significant difference in the university students' online information searching strategies between context A (for learning) and context B (for daily life). The second stage includes sampling and implementation of qualitative analysis interviews in order to understand the causes of the differences. The following are the results of the analysis.

\section{Differences in online information searching strategies between context $A$ and context B for all students}

Table 1 summarised the results of the paired t-tests on all subjects' OISSI sub-scores between context A and context B. Overall, after the justifications of significant levels, significant differences were found in Behavioural $(\mathrm{p}<.0001)$ and Metacognitive $(p<.001)$ domain scores between contexts A and B. Within the Behavioural domain, significant differences were found in both CON $(p<.005)$ and DIS $(p<.0001)$ aspects between the two contexts. As for the Metacognitive domain, a significant difference was only found in the EVA $(p<.001)$ aspect strategy. Scores of context B were all higher than those of context $\mathrm{A}$ in all of the above domains and aspects. Therefore, university students, in general, had significantly better behavioural and metacognitive strategies to search for daily life information than those used to search for learning information through the Internet. When looking into the specific strategies in these domains, it was found that the differences came from students' control, disorientation and evaluation strategies. That is, university students tend to have better control, orientation and evaluation strategies when searching information online for entertainment rather than for learning.

These results also indicated that, in general, university students' online information searching strategies utilised in context B (for daily life) were better than those utilised in context A (for learning), especially in Behavioural and Metacognitive domain strategies. An interesting observation was that all scale or domain means were higher than 4 in spite of the mean being 3.75 for DIS subscale of context A. This significantly low score could suggest that, in general, students might have orientation problems while information searching on the Internet for learning but not for daily life. 
Table 1: The paired t-tests on OISSI scores between contexts for all students

\begin{tabular}{|c|c|c|c|c|c|c|}
\hline OISSI & Context & $\mathrm{N}$ & Mean/Item & SD & $\mathrm{t}$ & $\mathrm{p}$ \\
\hline \multirow[t]{2}{*}{ Behavioural } & A & 285 & 4.20 & 0.82 & \multirow[t]{2}{*}{-6.63} & \multirow[t]{2}{*}{$0.0000^{* * *}$} \\
\hline & B & 285 & 4.44 & 0.83 & & \\
\hline \multirow[t]{2}{*}{$\mathrm{CON}$} & $\mathrm{A}$ & 288 & 4.65 & 0.91 & \multirow[t]{2}{*}{-3.01} & \multirow[t]{2}{*}{$0.0029^{*}$} \\
\hline & B & 288 & 4.77 & 0.94 & & \\
\hline \multirow[t]{2}{*}{ DIS } & $\mathrm{A}$ & 287 & 3.75 & 1.17 & \multirow[t]{2}{*}{-5.73} & \multirow[t]{2}{*}{$0.0000^{\star * *}$} \\
\hline & B & 287 & 4.10 & 0.91 & & \\
\hline \multirow[t]{2}{*}{ Procedural } & $\mathrm{A}$ & 287 & 4.36 & 0.85 & \multirow[t]{2}{*}{0.28} & \multirow[t]{2}{*}{0.7759} \\
\hline & B & 287 & 4.35 & 0.90 & & \\
\hline \multirow[t]{2}{*}{$\mathrm{TE}$} & $\mathrm{A}$ & 289 & 4.57 & 1.21 & \multirow[t]{2}{*}{1.09} & \multirow[t]{2}{*}{0.2778} \\
\hline & B & 289 & 4.51 & 1.11 & & \\
\hline \multirow[t]{2}{*}{ PS } & $\mathrm{A}$ & 289 & 4.16 & 0.92 & \multirow[t]{2}{*}{-0.96} & \multirow[t]{2}{*}{0.3401} \\
\hline & B & 289 & 4.20 & 0.91 & & \\
\hline \multirow[t]{2}{*}{ Meta-cognitive } & $\mathrm{A}$ & 279 & 4.36 & 0.83 & \multirow[t]{2}{*}{-3.39} & \multirow[t]{2}{*}{$0.0008^{* *}$} \\
\hline & B & 279 & 4.50 & 0.84 & & \\
\hline \multirow[t]{2}{*}{ PPT } & A & 288 & 4.39 & 0.90 & \multirow[t]{2}{*}{-2.16} & \multirow[t]{2}{*}{0.0315} \\
\hline & B & 288 & 4.50 & 0.93 & & \\
\hline \multirow[t]{2}{*}{ SMI } & A & 286 & 4.55 & 0.91 & \multirow[t]{2}{*}{-2.76} & \multirow[t]{2}{*}{0.0062} \\
\hline & B & 286 & 4.68 & 0.95 & & \\
\hline \multirow[t]{2}{*}{ EVA } & A & 287 & 4.18 & 0.98 & \multirow[t]{2}{*}{-3.73} & \multirow[t]{2}{*}{$0.0002^{* *}$} \\
\hline & B & 287 & 4.38 & 0.98 & & \\
\hline
\end{tabular}

${ }^{*} \mathrm{p}<0.005^{* *} \mathrm{p}<0.001{ }^{* * *} \mathrm{p}<0.0001$ (significant levels have been adjusted for multiple t-tests)

\section{Differences in online information searching strategies between context $A$ and context B for male students}

In order to examine if the above significant difference came from male students, this study analysed paired t-tests for male students (Table 2).

Table 2: The paired t-tests on OISSI scores between contexts for male students

\begin{tabular}{|c|c|c|c|c|c|c|}
\hline OISSI & Context & $\mathrm{N}$ & Mean/Item & SD & $\mathrm{t}$ & $\mathrm{p}$ \\
\hline \multirow[t]{2}{*}{ Behavioural } & A & 186 & 4.28 & 0.86 & -5.20 & $0.0000^{* * *}$ \\
\hline & B & 186 & 4.52 & 0.86 & & \\
\hline \multirow[t]{2}{*}{$\mathrm{CON}$} & A & 189 & 4.71 & 0.92 & -1.54 & 0.1246 \\
\hline & B & 189 & 4.80 & 0.96 & & \\
\hline \multirow[t]{2}{*}{ DIS } & A & 187 & 3.84 & 1.24 & -5.22 & $0.0000^{* * *}$ \\
\hline & B & 187 & 4.24 & 1.29 & & \\
\hline \multirow[t]{2}{*}{ Procedural } & A & 188 & 4.43 & 0.85 & -0.02 & 0.9866 \\
\hline & B & 188 & 4.43 & 0.89 & & \\
\hline \multirow[t]{2}{*}{ TE } & A & 189 & 4.62 & 1.04 & 0.47 & 0.6406 \\
\hline & B & 189 & 4.59 & 1.09 & & \\
\hline \multirow[t]{2}{*}{ PS } & A & 190 & 4.24 & 0.93 & -0.70 & 0.4857 \\
\hline & B & 190 & 4.28 & 0.92 & & \\
\hline \multirow[t]{2}{*}{ Meta-cognitive } & A & 181 & 4.40 & 0.86 & -2.44 & 0.0158 \\
\hline & B & 181 & 4.52 & 0.85 & & \\
\hline \multirow[t]{2}{*}{ PPT } & A & 188 & 4.40 & 0.94 & -2.28 & 0.0239 \\
\hline & B & 188 & 4.54 & 0.95 & & \\
\hline \multirow[t]{2}{*}{ SMI } & A & 187 & 4.61 & 0.93 & -1.40 & 0.1637 \\
\hline & B & 187 & 4.70 & 0.95 & & \\
\hline \multirow[t]{2}{*}{ EVA } & $\mathrm{A}$ & 188 & 4.24 & 1.00 & -2.17 & 0.0314 \\
\hline & B & 188 & 4.38 & 1.00 & & \\
\hline
\end{tabular}

${ }^{*} \mathrm{p}<0.005 ;{ }^{* *} \mathrm{p}<0.001 ;{ }^{* * *} \mathrm{p}<0.0001$ (significant levels have been adjusted for multiple t-tests) 
Table 2 showed that, for university male students, there were significant differences in the Behavioural $(p<.0001)$ and DIS $(p<.0001)$ scores between context A and context B. The significant negative $t$ values indicated that the mean scores for context $A$ were significantly smaller than those for context B. This finding suggested that male students had significantly better behavioural domain strategies used in context B (for daily life) than those used in context A (for learning), particularly in the disorientation aspect strategy. In other words, the university male students tended to get lost more often while searching for learning than searching for daily life information.

\section{Differences in online information searching strategies between context $A$ and context B for female students}

The results of the paired t-tests for female students are given in Table 3. It was noticed that significant differences were found not only in the sub-scores of the Behavioural domain but also in one of the Metacognitive domain. It is clear that the significant difference of the Meta-cognitive domain resulted from the EVA $(p<.005)$ score. As for the significance of the behavioural domain, the major contribution was due mainly to the CON $(p<.005)$ score. The significant negative $t$ values also indicated that the mean scores for context A were significantly smaller than the corresponding mean scores for context B. These results indicated that female students had better behavioural strategies, especially the control strategy, used for context B (for daily life) than those used for context A (for learning). At the same time, the female students had a significantly better evaluation strategy for evaluating online daily life information than for learning.

Table 3: The paired t-tests on OISSI scores between contexts for female students

\begin{tabular}{|c|c|c|c|c|c|c|}
\hline OISSI & Context & $\mathrm{N}$ & Mean/Item & SD & $\mathrm{t}$ & $\mathrm{p}$ \\
\hline \multirow{2}{*}{ Behavioural } & $\mathrm{A}$ & 99 & 4.05 & 0.72 & \multirow[t]{2}{*}{-4.14} & \multirow{2}{*}{$\frac{r}{0.0000^{* * *}}$} \\
\hline & B & 99 & 4.29 & 0.77 & & \\
\hline \multirow[t]{2}{*}{$\mathrm{CON}$} & $\mathrm{A}$ & 99 & 4.52 & 0.88 & \multirow[t]{2}{*}{-3.23} & \multirow[t]{2}{*}{$0.0017^{*}$} \\
\hline & B & 99 & 4.73 & 0.88 & & \\
\hline \multirow[t]{2}{*}{ DIS } & A & 100 & 3.59 & 1.00 & \multirow[t]{2}{*}{-2.55} & \multirow[t]{2}{*}{0.0124} \\
\hline & B & 100 & 3.84 & 1.28 & & \\
\hline \multirow[t]{2}{*}{ Procedural } & $\mathrm{A}$ & 99 & 4.24 & 0.83 & \multirow[t]{2}{*}{0.50} & \multirow[t]{2}{*}{0.6151} \\
\hline & B & 99 & 4.20 & 0.89 & & \\
\hline \multirow[t]{2}{*}{ TE } & $\mathrm{A}$ & 100 & 4.48 & 1.02 & \multirow[t]{2}{*}{1.09} & \multirow[t]{2}{*}{0.2788} \\
\hline & B & 100 & 4.36 & 1.13 & & \\
\hline \multirow[t]{2}{*}{ PS } & $\mathrm{A}$ & 99 & 3.99 & 0.90 & \multirow[t]{2}{*}{-0.66} & \multirow[t]{2}{*}{0.5107} \\
\hline & B & 99 & 4.04 & 0.87 & & \\
\hline \multirow[t]{2}{*}{ Meta-cognitive } & $\mathrm{A}$ & 98 & 4.28 & 0.76 & \multirow[t]{2}{*}{-2.36} & \multirow[t]{2}{*}{0.0203} \\
\hline & B & 98 & 4.47 & 0.82 & & \\
\hline \multirow[t]{2}{*}{ PPT } & A & 100 & 4.37 & 0.82 & \multirow[t]{2}{*}{-0.68} & \multirow[t]{2}{*}{0.4984} \\
\hline & B & 100 & 4.44 & 0.91 & & \\
\hline \multirow[t]{2}{*}{ SMI } & $\mathrm{A}$ & 99 & 4.43 & 0.87 & \multirow[t]{2}{*}{-2.72} & \multirow[t]{2}{*}{0.0077} \\
\hline & B & 99 & 4.66 & 0.96 & & \\
\hline \multirow[t]{2}{*}{ EVA } & $\mathrm{A}$ & 99 & 4.08 & 0.94 & \multirow[t]{2}{*}{-3.36} & \multirow[t]{2}{*}{$0.0011^{*}$} \\
\hline & B & 99 & 4.39 & 0.93 & & \\
\hline
\end{tabular}

In summary, both male and female university students showed significant better behavioural domain strategies utilised in context B (for daily life) than those utilised in context A (for learning). However, in the behavioural domain, male students showed 
differences in the disorientation aspect while female students displayed difference in the control aspect. No significant difference was found in either male or female university students' procedural domain strategies for online searching between the two contexts. As for the meta-cognitive domain strategies, only the female students had a significantly better strategy in evaluating online information for context B (for daily life) than that for context A (for learning). All of the above may suggest that search context could play different roles in different dimensions of the online information searching strategies between male and female students.

\section{Interview analysis of differences of online information searching strategies between context $A$ and context $B$}

Following upon the above quantitative analysis findings, this study continued with a second-stage qualitative interview analysis on the significant differences found in the strategies (i.e., behavioural and metacognitive strategies) to learn more about the causes of the differences. The researchers sampled and interviewed 20 students from the initial trial individuals. The following is the compilation of the analysis done on the interviews, citing students' interview transcripts to verify the differences found.

First, in the control aspect of the behavioural strategies, the students indicated in the interviews that it was harder to search for information in context A (for learning), because when searching for the more complex study-oriented information, students often suffered from retardation in thinking and control aspect, making the search more difficult. Daily life information is usually on life-related issues, it is abundant and easier to search for, and therefore displays a better control aspect. The following are excerpts from the interviews.

\#s003: I tend to be slow at learning context and encounter problems easily because I find the (study related) content of the work or the work itself difficult.

\#s020: Because it's... it's just easier to find daily life information...If you try to find something more in-depth for the study, it's more difficult, a lot more difficult! Because ... because it's (daily life information) what everybody often encounters, that is, there is more relevant information.

In the disorientation aspect of the behavioural strategies, the students expressed that searching study-oriented information often caused tension and stress, as well as disorientation or the tendency to forget the main search gist when facing unspecific instruction for the task. Daily life information searching was motivated by students' eagerness to solve problems, so it was relaxing, and thus minimising the disorientation problems. The following are some excerpts from the interviews.

\#s018: Daily life information is what you want to know, so you want to look for it...study is what the teachers assign you to do, so have to search for it, therefore, sometimes you won't know what you need to find ... Because sometimes you simply don't understand what the teachers want ...

\#s021...Sometimes you would feel there is so much (study-related information) to search for, what do the teachers really want? There is just too much relevant information available, where do I start? Where do I go about finding it?

\#s020: Emotion-wise, yeah, I get nervous, then I forget (the search gist or direction.) 
In the evaluation aspect of the metacognitive strategies, the students indicated that when searching for study-related information, merely finding an answer was good enough; on the other hand, when searching for daily life information, they wanted to understand more and do a more in-depth evaluation.

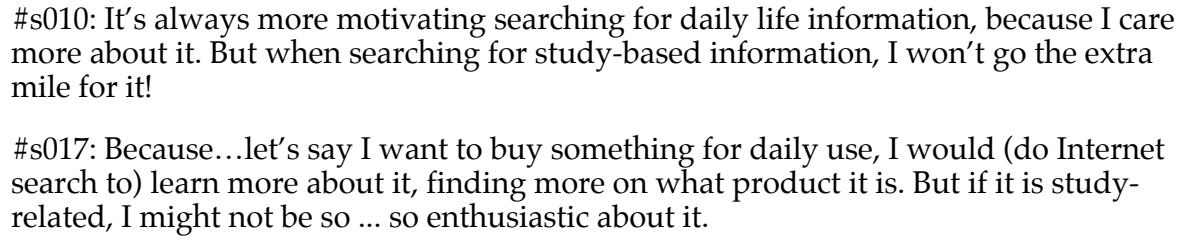

The analysis of these interviews provided us with more understanding on why the students showed better performance on the above mentioned aspects (i.e., control, disorientation, evaluation) of daily life information searching compared with the study-specified situation.

\section{Discussion}

Based on the above results, this study suggests that university students in general tended to perceive better online searching strategies for daily life than for learning topics. The major differences were shown in behavioural and metacognitive domain strategies, including orientation perception, systematic control and information evaluation strategies. However, no significant differences were found in procedural domain strategies. This suggested that procedural domain strategies could be contextneutral, while behavioural and metacognitive domain strategies could be contextdependent, i.e. depending on students' prior knowledge and experiences relating to a specific search context or topic. According to the interview results, this study further verified that control retardation, anxiety and disorientation often occurred when students were confronted with difficult tasks, limited motivation and instructional confusion while searching for study-related information. Better control and in-depth evaluation strategies shown in their daily life information search were due mainly to online information availability, students' high level of motivation, and related experience. This result is similar to recent findings that fundamental searching strategies were enough for well-structured problem solving; however, a training on advanced searching strategies is required for ill-structured problem solving (Laxman, 2010). In addition, everyday enquiries are usually in more familiar topics, and with simpler tools, like Google. Learning enquiries, however, involves less familiar concepts, and with more complex tools, for example ProQuest. Therefore, it is reasonable to see such a result. Another possible reason for this finding may be due to an interaction with students' insufficient self-efficacy toward online learning (Tsai, 2009a); however, a further examination is needed to explain this possibility.

In response to these findings, we suggest that when teachers implement online information searching activities, the learning tasks can assimilate interesting topics designed from a variety of life experiences and data. We also suggest that teachers clearly define the task assigned and give students ample time for information collection, avoiding anxiety caused by time limits. In addition, teachers are also encouraged to incorporate online problem-solving activities with the proposed task to encourage dialogical or multi-voiced argumentation (Driver, Newton \& Osborne, 2000), thus promoting more in-depth evaluation on the information. Through mutual support and collaborative interaction, students are expected to be relieved from the 
pressure caused by unaided information searching and disorientation. Meanwhile, teachers may also consider applying role-playing or problem solving strategies to improve learning motivation. Role-playing method allows students to play a variety of specific roles, which aims to simulate daily life scenarios, helping students gain more experience from daily life information search contexts. Prior studies have found that such teaching methods can help improve students' motivation (Wishart et al., 2007), communication skills and team decision-making capacity (Bos \& Shami, 2006; Chien et al., 2003; Pata \& Lehtinen, 2005). A recent study (Laxman, 2009) has attempted to document the Internet information search proficiencies for Singapore students, to emphasise the importance of information literacy skills within school curriculum. Future research can conduct more in-depth analysis on students' information searching behaviours when employing the above mentioned teaching strategies.

Another conclusion from this study is that there might be an effect of the interaction between search context and gender on students' online searching strategies. Based on the above results, when the search strategies were examined between contexts separately by gender, the significant difference in the metacognitive domain strategies was found only within the female students, and this difference came mainly from their evaluation strategies. This indicated that university female students might be more readily influenced by contexts than male students when they search and evaluate information through the Internet. Although several studies have examined gender differences in online usage or search strategies (Large, Beheshti \& Rahman, 2002; Liang \& Tsai, 2009; Roy \& Chi, 2003; Tsai, 2009b; Tsai \& Tsai, 2010), little research has been reported regarding the relationships between gender, metacognitive strategies and online information evaluation. Therefore, future research should also examine the factors influencing students' metacognitive strategies for online information searching, for example, prior domain knowledge and personal epistemological beliefs.

Recently, Tsai, Hsu \& Tsai (2012) examined and discussed students' online information searching strategies from both implicit and explicit perspectives. Implicit strategies indicate students' cognitive strategies which are implicitly utilised by individuals during online searching and can be reflected by self-reported survey, interviews or think-aloud protocols (Tsai, 2009b; Tsai \& Tsai, 2003). Explicit strategies refer to students' behavioural strategies which are explicitly exhibited in individual searching actions and can be observed by screen-captured videos or log-files (e.g., Hwang, Tsai, Tsai \& Tseng, 2008; Lin \& Tsai, 2007; Tsai \& Tsai, 2003). The present study used selfreported surveys and interviews to examine students' implicit strategies for two different search contexts. Future studies could combine both implicit and explicit approaches to better understand students' online inquiry process. Meanwhile, recent studies have begun to use new research tools such as eye-trackers to explore deeply students' visual attentions and implicit cognitive strategies utilised in digital learning environments (e.g., Tsai, Hou, Lai, Liu \& Yang, 2012). Therefore, future studies are also suggested using eye-tracking techniques to investigate students' implicit strategies for online search. Also, progressive sequential analysis (Hou, 2010) could be used to better understand the sequential patterns of students' online searching behaviours.

\section{Acknowledgments}

This study was supported by the National Science Council, Taiwan, under the following project numbers: NSC-99-2511-S-011-005-MY3, NSC-99-2511-S-011-006-MY3, NSC-99-2511-S-011-007-MY3, NSC-99-2511-S-011-008-MY3. 


\section{References}

Bond, C. S., Fevyer, D. \& Pitt, C. (2006). Learning to use the Internet as a study tool: A review of available resources and exploration of students' priorities. Health Information and Libraries Journal, 23(3), 189-196. http: / / dx.doi.org/10.1111/j.1471-1842.2006.00656.x

Bos, N. (2000). High school students' critical evaluation of scientific resources on the World Wide Web. Journal of Science Education and Technology, 9(2), 161-173. http:/ / dx.doi.org/10.1023/ A:1009426107434

Bos, N. \& Shami, N. S. (2006). Adapting a face-to-face role-playing simulation for online play. Educational Technology Research and Development, 54(5), 493-521. http: / / dx.doi.org/ 10.1007/ s11423-006-0130-z

Chen, L. D., Muthitacharoen, A. M. \& Frolick, M. N. (2003). Investigating the use of role play training to improve the communication skills of IS professionals: Some empirical evidence. The Journal of Computer Information Systems, 43(3), 67-74. http: / / www.highbeam.com/ doc/1P3-336085321.html

Chou, C. \& Tsai, M.-J. (2007). Gender differences in Taiwan high school students' computer game playing. Computers in Human Behavior, 23(1), 812-824. http: / / dx.doi.org/10.1016/j.chb.2004.11.011

Chu, S. K. W. \& Law, N. (2008). The development of information search expertise of research students. Journal of Librarianship and Information Science, 40(3), 165-177. http: / / dx.doi.org/10.1177/0961000608092552

Corredor, J. (2006). General and domain-specific influence of prior knowledge on setting of goals and content use in museum websites. Computers $\mathcal{E}$ Education, 47(2), 207-221. http:/ / dx.doi.org/10.1016/j.compedu.2004.10.010

Debowski, S. (2001). Wrong way: Go back! An exploration of novice search behaviours while conducting an information search. The Electronic Library, 19(6), 371-382. http: / / dx.doi.org/10.1108/02640470110411991

Dias, P., Gomes, M. J. \& Correia, A. P. (1999). Disorientation in hypermedia environments: Mechanisms to support navigation. Journal of Educational Computing Research, 20(2), 93-117. http: / / dx.doi.org/10.2190/ G8C5-342V-DJX3-Q53F

Driver, R., Newton, P., \& Obsorne, J. (2000). Establishing the norms of scientific argumentation in classrooms. Science Education, 84(3), 287-312. http:/ / dx.doi.org/10.1002/(SICI)1098237X(200005)84:3<287::AID-SCE1>3.3.CO;2-1

Fleiszer, D. M. \& Posel, N. H. (2003).Development of an undergraduate medical curriculum: The McGill experience. Academic Medicine, 78(3), 265-269. http:/ / journals.lww.com/academic medicine $/$ pages $/$ articleviewer.aspx? year $=2003 \&$ issue $=03000 \&$ article $=00005 \&$ type $=$ abstract

Glass, G. V. \& Hopkins, K. D. (1996). Statistical methods in education and psychology (3rd ed.). Needham Heights, MA: Allyn \& Bacon.

Hill, J. R. (1999). A conceptual framework for understanding information seeking in open-ended information systems. Educational Technology Research and Development, 47(1), 5-27. http: / / dx.doi.org/10.1007/BF02299474

Hou, H. T. (2010) Exploring the behavioural patterns in project-based learning with online discussion: Quantitative content analysis and progressive sequential analysis. Turkish Online Journal of Educational Technology, 9(3), 52-60. http: / / www.tojet.net/articles / v9i3/935.pdf

Hwang, G.-J., Tsai, P.-S., Tsai, C.-C., \& Tseng, J. C. R. (2008). A novel approach for assisting teachers in analyzing student web searching behaviors. Computers $\mathcal{E}$ Education, 51(2), 926-938. http: / / dx.doi.org/10.1016/j.compedu.2007.09.011 
Keasar, T., Baruch, R. \& Grobgeld-Dahan, E. (2005). An evaluation of web enhanced instruction in college level biology courses. Australasian Journal of Educational Technology, 21(4), 533-545. http: / / www.ascilite.org.au/ajet/ajet21/keasar.html

Kim, K. S. (2001). Implications of user characteristics in information seeking on the World Wide Web. International Journal of Human-Computer Interaction, 13(3), 323-340. http: / / dx.doi.org/10.1207/S15327590IJHC1303_3

Large, A., Beheshti, J. \& Rahman, T. (2002). Gender differences in collaborative Web searching behavior: An elementary school study. Information Processing \& Management, 38(3), 427-443. http: / / dx.doi.org/10.1016/S0306-4573(01)00034-6

Levine, A. E., Bebermeyer, R. D., Chen, J. W., David, D. \& Harty, C. (2008). Development of an interdisciplinary course in information resources and evidence-based dentistry. Journal of Dental Education, 72(9), 1067-1076. http: / / www.jdentaled.org/content/72/9/1067.full.pdf

Laxman, K. (2010). A conceptual framework mapping the application of information search strategies to well and ill-structured problem solving. Computers \& Education, 55(2), 513-526. http: / / dx.doi.org/10.1016/j.compedu.2010.02.014

Laxman, K. (2009). A baseline study on the Internet information search proficiencies of polytechnic students in Singapore. International Journal of Education and Development using ICT, 5(3). http: / / ijedict.dec.uwi.edu / / viewarticle.php?id=936

Li, Q. (2005). Gender and CMC: A review on conflict and harassment. Australasian Journal of Educational Technology, 21(3), 382-406. http: / / www.ascilite.org.au/ajet/ajet21/li.html

Liang, J. C. \& Tsai, C.-C. (2009). The information commitments toward web information among medical students in Taiwan. Educational Technology and Society, 12(1), 162-172. http: / / www.ifets.info/ abstract.php?art_id=917

Lin, C.-C. \& Tsai, C.-C. (2007). A navigation flow map method of representing students' searching behaviors and strategies on the Web, with relations to searching outcomes. CyberPsychology E Behavior, 10(5), 689-695. http:/ / dx.doi.org/10.1089/ cpb.2007.9969

Marchionini, G. (1995). Information seeking in electronic environments. New York: Cambridge University Press.

McGreevy, P., Shaw, T., Burn, D. \& Miller, N. (2007). OLIVER: An online library of images for veterinary education and research. Journal of Veterinary Medical Education, 34(4), 510-516. http: / / dx.doi.org/10.3138/jvme.34.4.510

Pata, K., Sarapuu, T. \& Lehtinen, E. (2005). Tutor scaffolding styles of dilemma solving in network-based role-play. Learning and Instruction, 15(6), 571-587. http: / / dx.doi.org/10.1016/j.learninstruc.2005.08.002

Phelps, R., Fisher, K. \& Ellis, A. (2006). Organisational and technological skills: The overlooked dimension of research training. Australasian Journal of Educational Technology, 22(2), 145-165. http: / / www.ascilite.org.au/ajet/ajet22/phelps.html

Rieh, S. Y. (2002). Judgement of information quality and cognitive authority in the Web. Journal of the American Society for Information Science and Technology, 53(2), 145-161. http: / / dx.doi.org/10.1002/ asi.10017

Roy, M. \& Chi, M. T. H. (2003). Gender differences in patterns of searching the Web. Journal of Educational Computing Research, 29(3), 335-348. http: / / dx.doi.org/10.2190/7BR8-VXA0-07A7$8 \mathrm{AVN}$

Tekinarslan, E. (2008). Blogs: A qualitative investigation into an instructor and undergraduate students' experiences. Australasian Journal of Educational Technology, 21(4), 402-412. http: / / www.ascilite.org.au/ajet/ajet24/tekinarslan.html 
Thatcher, A. (2008). Web search strategies: The influence of web experience and task type. Information Processing \& Management, 44(3), 1308-1329. http: / / dx.doi.org/10.1016/j.ipm.2007.09.004

Tsai, M.-J. (2009a). The model of strategic e-learning: Understanding and evaluating student elearning from metacognitive perspectives. Educational Technology and Society, 12(1), 34-48. http: / / www.ifets.info / index.php?http:/ / www.ifets.info/abstract.php?art_id=908

Tsai, M.-J. (2009b). Online Information Searching Strategy Inventory (OISSI): A quick version and a complete version. Computers $\mathcal{E}$ Education, 53(2),473-483. http: / / dx.doi.org/10.1016/j.compedu.2009.03.006

Tsai, M.-J. \& Tsai, C.-C. (2003). Information searching strategies in web-based science learning: The role of Internet self-efficacy. Innovations in Education and Teaching International, 40(1), 4350. http: / / dx.doi.org/10.1080/1355800032000038822

Tsai, M.-J. \& Tsai, C.-C. (2010). Junior high school students' Internet usage and self-efficacy: A reexamination of the gender gap. Computers $\mathcal{E}$ Education, 54(4), 1182-1192. http:/ / dx.doi.org/10.1016/j.compedu.2009.11.004

Tsai, M.-J., Hou, H. T., Lai, M. L., Liu, W.-Y. \& Yang, F. Y. (2012). Visual attention for solving multiple-choice science problem: An eye-tracking analysis. Computers $\mathcal{E}$ Education, 58(1), 375385. http:/ / dx.doi.org/10.1016/j.compedu.2011.07.012

Tsai, M.-J., Hsu, C.-Y. \& Tsai, C.-C. (2012). Investigation of high school students' online science information searching performance: The role of implicit and explicit approaches. Journal of Science Education and Technology, 21(2), 246-254. http:/ / dx.doi.org/10.1007/ s10956-011-9307-2

Tu, Y. W., Shih, M. \& Tsai, C.-C. (2008). Eighth graders' web searching strategies and outcomes: The role of task types, web experiences and epistemological beliefs. Computers $\mathcal{E}$ Education, 51(3), 1142-1153. http: / / dx.doi.org/10.1016/j.compedu.2007.11.003

Walraven, A., Brand-gruwel, A. \& Boshuizen, P. A. H. (2008). Information-problem solving: A review of problems students encounter and instructional solutions. Computers in Human Behavior, 24(3), 623-648. http: / / dx.doi.org/10.1016/j.chb.2007.01.030

Wishart, J. M., Oades, C. E. \& Morris, M. (2007). Using online role play to teach Internet safety awareness. Computers $\mathcal{E}$ Education, 48(3), 460-473.

http: / / dx.doi.org/10.1016/j.compedu.2005.03.003

\section{Appendix: The Online Information Searching Strategies Inventory (OISSI) for two search contexts}

$1=$ Not like me at all

$2=$ Not very much like me

$3=$ Somewhat not like me

$4=$ Somewhat like me

$5=$ Like me

$6=$ Very much like me

For all of the 25 items, please consider and respond to the following two search contexts:

Context A: When I search information on the Internet for learning, e.g. for doing homework ......

Context B: When I search information on the Internet for daily life, e.g. for updating entertainment news of pop singers...... 
1. I know how to use a web browser, like IE or Netscape.

2. I look through the titles or hyperlinks in order to catch the main ideas in a webpage.

3. I know how to utilise advanced-search functions provided by search engines.

4. I know how to login a specific website with its URL.

5. I usually think about what keywords I can use in advance.

6. I select main ideas provided in each webpage as possible as I can.

7. I look through titles or hyperlinks in a web in order to catch major information.

8. I think of how to present and organise the data that I have searched from the web.

9. I keep on evaluating the relationships among the data searched from the web.

10. I compare information that has been collected from different websites

11. I decide if the information provided in a website is worth for reference.

12. I keep on reminding myself of the purpose for searching online.

13. I think of how to utilise the searched information.

14. I usually make sure the goals before starting my online searching.

15. Sometimes, I stop and think about what information is still lacking.

16. I always feel nervous while searching.

17. I don't know how to start my online searching.

18. I always feel lost while searching.

19. I don't know what to do during my searching.

20. I try some possible entrance websites when I cannot find enough information.

21. I try other databases when I cannot get any information in one database.

22. I try some other search engines when my search is not successful.

23. I usually give up searching when I come up with unsolved problems.

24. I think of some resolutions when I am frustrated with searching problems.

25. I do my best to resolve any problem occurred during a searching.

Authors: Meng-Jung Tsai, Professor

Graduate Institute of Digital Learning and Education

National Taiwan University of Science and Technology, Taipei, Taiwan

43, Sec. 4, Keelung Rd., Taipei, 106, Taiwan. Email: mjtsai99@mail.ntust.edu.tw

Jyh-Chong Liang, Associate Professor

Graduate Institute of Applied Science and Technology

National Taiwan University of Science and Technology, Taipei, Taiwan

43, Sec. 4, Keelung Rd., Taipei, 106, Taiwan. Email: aljc@mail.ntust.edu.tw

Huei-Tse Hou, Assistant Professor

Graduate Institute of Applied Science and Technology

National Taiwan University of Science and Technology, Taipei, Taiwan

43, Sec. 4, Keelung Rd., Taipei, 106, Taiwan. Email: hthou@mail.ntust.edu.tw

Chin-Chung Tsai, Chair Professor (corresponding author)

Graduate Institute of Digital Learning and Education

National Taiwan University of Science and Technology, Taipei, Taiwan

43, Sec. 4, Keelung Rd., Taipei, 106, Taiwan. Email: cctsai@mail.ntust.edu.tw

Please cite as: Tsai, M.-J., Liang, J.-C., Hou, H.-T. \& Tsai, C.-C. (2012). University students' online information searching strategies in different search contexts. Australasian Journal of Educational Technology, 28(5), 881-895.

http: / / www.ascilite.org.au/ajet/ajet28/tsai-mj.html 